\title{
Mito y Realidad en Los Ojos de los Enterrados, de Miguel Angel Asturias
}

Uno de los problemas fundamentales de la novela moderna es el de las relaciones entre la realidad que circunda a los hombres y la conciencia que éstos tienen de ella. En algunos autores y críticos este problema se presenta en la interpretación existencialista de la dicotomía de la realidad exterior y la interior o humana, del hombre.

En una forma bastante original, las relaciones entre la realidad y la conciencia de los hombres caracterizan lo que en la novela latinoamericana se dio en llamar "realismo mágico", del que Miguel Angel Asturias es uno de los mayores representantes.

Los críticos hablan a menudo de "dos vertientes que alimentan... la obra de Miguel Angel Asturias, la mitológica y la realista", ${ }^{1}$ y Luis Justo cree que estas dos vertientes representan dos elementos espirituales, el europeo (racional) y el indio (mágico), que coexisten en ia mente del autor. ${ }^{2}$ Sin embargo, el propio Asturias declara que su obra se fundamenta en una concepción más dialéctica y profunda.

En numerosos reportajes se destaca que Asturias habla constantemente de la "solidaridad... entre el escritor y su pueblo", ${ }^{3}$ deduciendo de eso la tarea fundamental del escritor latinoamericano:

En la obra a realizar en América, el escritor debe buscar, de preferencia, el tema americano y llevarlo a su obra literaria con lenguaje americano. Este lenguaje americano no es el uso del modismo, sim-

1 M. A. Asturias, Mulata de tal (Buenos Aires, 1963), texto de la sobrecubierta.

2 L. Justo, "Miguel Angel Asturias: Mulata de zal", en Cuadernos del Congreso por la Libertad de la Cultura, no 81, febrero 1964, p. 91 .

" J. Corrales Egea, "Tres escritores hispanoamericanos en París. II: Miguel Angel Asturias", en Insula, n' 197, p. 12. 
plemente. Es la interpretación que la gente de la calle hace de la realidad que vive: desde la tradición hasta sus propias aspiraciones populares. ${ }^{4}$

Estas observaciones confirman lo siguiente: Asturias, que muchas veces habia dicho que "la miseria de estas poblaciones" era la base de todas sus obras, exige la representación de la realidad americana en su totalidad a la vez material y espiritual. Es de importancia que Asturias se refiera específicamente a los pueblos de América Latina, es decir, a los seres humanos, y no principalmente a las distintas formas de la realidad objetiva americana, inclusive las condiciones en que viven los hombres. De ese modo, el tema americano deviene sobre todo la conciencia $y$ autoconciencia de los hombres de extracción popular. Este fundamento posibilita que el autor supere con obras de una nueva categoría las variantes de la novelística latinoamericana anterior, como la costumbrista, la naturalista y buena parte de la indigenista.

A base de estas premisas proporcionadas por el propio Asturias, resulta interesante analizar las relaciones entre mito y realidad en una de sus novelas marcadamente "sociales", Los ojos de los enterrados, que corona su conocido ciclo bananero.

El tema fundamental de todas las novelas de Asturias es directa o indirectamente el pueblo, ${ }^{5}$ sobre todo la población campesino-india en la "interpretación que... hace de la realidad que vive". La conciencia de la población campesina de los paises latinoamericanos está compenetrada de elementos numerosos, que nacen de las peculiaridades de la confrontación con la naturaleza, de tradiciones étnicas y de las condiciones de la sociedad semifeudal en que vive. Por consiguiente, el concepto del mundo que guía las acciones de esta población no es racional. En eso consiste la gran dificultad que Asturias tiene que dominar en sus obras:

...el hecho tan corriente entre nosotros... de sucesos reales que la imaginación popular transforma en leyendas o de leyendas que llegan a encarnar acontecimientos de la vida diaria. A mi me parece muy importante en el existir americano esa zona en que se confunden, sin límite alguno, la irrealidad real... de lo legendario con la vida misma de los personajes. ${ }^{\mathrm{B}}$

4 J. C., "Miguel Angel Asturias en Montevideo", en Repertorio Americano, 10 de marzo de 1950, p. 82.

5 Véase J. A. Castelpoggi (Miguel Angel Asturias, Buenos Aires, 1961), p. 66.

6 R. Trigueros de León, "Miguel Angel Asturias", en Perfil en el aire (San Salvador, 1955), p. 130. 
Así resulta que en la obra de Asturias no domina una vertiente de la dicotomía mencionada de lo mágico-espiritual y lo objetivo-real, sino una tendencia fundamental más homogénea: la representación de la realidad humana de América Latina en el sentido de la vida espiritual de la población, ${ }^{7}$ su conf tontación con el mundo y sus conflictos sociales. Eso es la "recreación del mundo americano"8 que constantemente ha preocupado a Asturias.

Es notable que esta preocupación costante se realice en la obra literaria de Asturias a base de un largo proceso cognoscitivo con respecto a los problemas de su pueblo. Así, la trayectoria de su obra parte de la fundamentación del ser guatemalteco en la unidad bifacética que constituyen la grandeza espiritual de las tradiciones en Leyendas de Guatemala, y la miseria espiritual presente en El Señor Presidente, y llega hasta Los ojos de los enterrados, abarcando el largo camino que va desde un humanismo espiritualista hasta posiciones francamente favorables a la revolución. Después de verse privado del contacto directo con la vida y lucha de su pueblo y Latinoamérica en general, el autor vuelve a recrear $\mathrm{cl}$ patrimonio mitológico y legendario de su pais en Mulata de tal y El es. pejo de Lida Sal.

Dentro de esta trayectoria ocupa un lugar destacado la trilogia bana. nera con Viento fuerte (1951), El papa verde (1954) y Los ojos de los enterrados (1960).

Viento fuerte es una obra contradictoria. Por un lado, el autor, según sus propias explicaciones, quiere transponer al terreno de la novela lo que leyó en el libro El imperio del banano, de Kepner y Soothill. Por otro lado, relaciona esta materia narrativa con la vida del pucblo y sus conceptos mágicos en los capítulos finales que describen el "viento fuerte" desencadenado por el brujo Rito Perraj. La génesis del libro explica que mito y realidad, en Viento ftierte, no están plasmados en una unidad perfectamente lograda.

En El papa verde estos dos elementos tampoco forman una unidad perfecta. Sin embargo, el autor descubre nuevas dimensiones del mito en el sentido de que éste no es tanto un concepto mágico sino más bien un anhelo a la libertad o a la realización de los hombres en la plenitud de la vida. Desde esta posición Asturias capta la dialéctica en la vida de Geo M. Thompson y crea nuevos mitos, sobre todo el de Mayari, la novia de Thompson que se suicidó en una noche de honda significa-

7 Véase V. N. Kuteišikova, Roman Latinskoj Amineriki v XX veke (Moscú, 1964), p. 268.

8 R. Trigueros de León, op. cit., p. 122. 
ción ritual para escapar al matrimonio con quien había quitado la tierra y -en un sentido más amplio, lo más hondo y esencial de la vida-, a sus compatriotas.

Al final de El papa verde los protagonistas y el lector se encuentran frente a muchos mitos derrumbados por una realidad cruel y el nucvo mito de Mayarí que se sacrificó trágicamente y sin resultado directo para su gente. El lector también sabe que entre los campesinos de Bananera cunde la rebelión. Con el grito de "Chos, chos, moyón con", ellos mantienen despierta su conciencia. La comparación de Viento fuerte y $\mathrm{El}$ papa verde muestra que Miguel Angel Asturias ha conservado el elemento central de su imagen del hombre, la idea de la esperanza como fuerza motriz de sus acciones. Pero el tratamiento de lo mágico ha cambiado. Así, el autor procede distintamente con la historia del viento fuerte y su motivación mágica. La retoma cuando Rito Perraj se queja resignadamente de que la tempestad le haya traído a la compañia bananera el maleficio, pero sin obsequiar al pueblo la justicia esperada." Sin embargo, más adelante, Rito Perraj es convertido en el guardián de la esperanza de la justicia: "Esperar que amanezca es tu papel supremo. Transmitir de generación en generación esta virtud de la esperanza, tu designio", ${ }^{10}$ y para la realización de esta misión Rito Perraj pronostica un "viento fuerte formado por masas humanas que barrerían con la "Tropicaltanera'..."."11 Con eso Asturias atribuye al mito, además de la representatividad nacional y popular, una relevancia social directa, empezando a convertir la conciencia mágica de sus protagonistas en una fuerza revolucionaria.

Este tratamiento del mito y la magia como elementos orientadores de la actuación social de los hombres culmina en Los ojos de los enterrados.

Ya en El papa verde hay una alusión a la leyenda de los muertos que cierran los ojos cuando hay justicia. ${ }^{12}$ Con esta leyenda, que no sólo pertenece al pueblo guatemalteco, sino que es conocida universalmente, se define la posición que el libro ocupa en la trilogía bananera. La novela expresará el comienzo de la edad de la justicia. La motivación se menciona en relación con la expulsión de los campesinos por Geo M. Thompson; la edad de la justicia, por ende, no se puede medir sino. por la reparación de este acto cometido contra el pueblo.

Por eso la perspectiva de esta novela ha cambiado considerablemente en comparación con las otras dos partes del ciclo. La trama de Los ojos de los enterrados resulta posible sólo cuando el pueblo guatemalteco,

${ }^{2}$ M. A. Asturias, El papa verde, 2a ed. (Buenos Aires, 1957), p. 164.

10 Ibid., p. 167.

11 Ibid., p. 267.

12 Ibid., p. 51. 
como protagonista activo, se convierte en el personaje central de la novela. De ahí que Asturias alcanza en este libro, como escribe Iverna Codina, "en esa línea ascendiente de la toma de conciencia de un pueblo... una magistral descripción de masas en marcha".13

La novela está obviamente construida sobre esta base conceptual, ya que su acción se extiende desde el fracaso de la huelga de los trabajadores en la costa del Atlántico hasta la caída de Ubico en 1944, y trata, en un sentido más estrecho, la expansión del movimiento huelguístico al territorio de la costa del Pacífico. ${ }^{14}$

La conexión indisoluble entre la dominación de la compañía frutera y la dictadura se fija claramente:

Derrocar a la fiera militar de turno dejando a la frutera intacta, era engañarse, y atacar a la compañía, con el dictadorzuelo encima, era imposible. Había que acabar con los dos al mismo tiempo. ${ }^{15}$

El movimiento empieza con demandas como el uso de la moneda nacional, el empleo del idioma español en vez del inglés, y el permiso de izar la bandera patria en vez de las franjas y estrellas. ${ }^{16}$ Con el correr del tiempo, el grito de "Chos, chos, moyón con" se convierte en el lema de la rebelión para todo el país. La realidad tratada en Los ojos de los enterrados es, pues, la de la revolución y sus causas.

Siendo así, no es de admitar que Asturias explore detalladamente y en varios lugares el problema de la revolución, entrelazándolo con consideraciones históricas. Su protagonista, Tabío San, participa primero en una conspiración para asesinat al dictador. Después del fracaso observa: "...operaba con gentes que no comprendian demasiado y no se les ocultaba que en una revuelta popular, ellos también peligraban, sobre todo sus intereses...".17 Más tarde comenta las manifestaciones estudiantiles contra Ubico: "Era comienzo de un tiempo de ficción", para continuar más adelante:

Hubiera querido no decit aquella frase literaria. Pero, ¡cómo designar de otra manera el paréntesis de luz que se abría en el cotidiano vivir de gentes de pan y sueño, sino como un tiempo de ficción democrática, si los trabajadores organizados no le daban un conte-

13 I. Codina, América en la novela (Buenos Aires, 1964), p. 59.

14 Véase M. A. Asturias, Los ojos de los enterrados, $2^{\mathbf{a}}$ ed. (Buenos Aires, 1961), p. 48.

15 Ibid, p. 250.

16 Véase M. A. Asturias, Los ojos de los enterrados, ed. cit., p. 376.

17 Ibid., p. 181. 
nido que fuera más allá del arrebato estrujador y embriagante de la libertad altibelisona... !18

El hecho de que en Los ojos de los enterrados Asturias dejó detrás las ideas liberales, se debe evidentemente al proceso cognoscitivo mencio. nado, cuya trayectoria se hace patente si se compara la obra de Asturias con las novelas de su contemporáneo guatemalteco más importante, Mario Monteforte Toledo. ${ }^{19}$

La posición y el objetivo del autor tienen consecuencias muy grandes para la elaboración de la novela. El problema que resulta de ello es múltiple: El autor tuvo que conectar la novela con sus predecesores, por lo cual son dados el lugar principal de la acción, Tiquisate, y un extenso grupo de personajes con una prehistoria correspondiente. Sin embargo, la revolución de 1944 tuvo lugar principalmente en la ciudad de Guatemala. Asturias resuelve el problema de manera que la confrontación de los trabajadores con el "trust" ocurre bajo la influencia de los acontecimientos en la capital. Esto facilitó la solución de otro problema: había que presentar cómo los obreros de Tiquisate se alistaron en el movimiento revolucionario. Por consiguiente era inevitable presentar a éste como un proceso que se extiende a Tiquisate y organiza a los trabajadores. La trama de Los ojos de los enterrados resulta de esta problemática. Dos asuntos se combinan y entretejen: el desarrollo del movimiento revolucionario en Guatemala -encarnado en los personajes de Tabío San y Malena Tabay- y el destino de los personajes de la región bananera ya conocidos por el lector.

Es interesante cómo en la historia de Tabío San y Malena Tabay, Asturias combina su humanismo integral con sus ideas sobre la revolución. En lo político, revolución quiere decir liberación de la dominación combinada de la empresa bananera y el dictador y reinstalación de la justicia perdida. Su medio, la huelga general, es considerada como "desintegración integradora", ${ }^{20}$ y la inquietud del pueblo está expresada por la paráfrasis del Pater noster: " ¡Nuestro pais de cada día, dádnoslo hoy!". 21 Eso revela que, según Asturias, detrás de la acción política existe un anhelo profundamente humano: la restitución de la esperanza, del mito y de la renovada posibilidad de una vida plenamente realizada. Por

18 Ibid., p. 393.

19 Tal comparación podria efectuarse con respecto a la perspectiva de las novelas, sobre todo a base de Donde acaban los caminos (1953) y Una manera de morir (1957).

20 Véase M. A. Asturias, Los ojos de los enterrados, ed. cit., p. 212.

$=2$ lbid., P. 442 . 
consiguiente, la revolución no es sólo un proceso socio-político, una empresa práctica, sino la liberación del hombre en todos los aspectos de su vida, en la totalidad de su humanidad.

Es obvio que en Los ojos de los enterrados Asturias continúa un humanismo integral que ya puede observarse en Viento fuerte y otras obras anteriores, pero lo sitúa en un contexto social visto de una manera diferente. Por eso hay un significado muy profundo cuando la leyenda de los ojos de los enterrados es interpretada del modo siguiente por un personaje secundario:

Sí, el día de la justicia resucitarán los muertos, pero no los que están bajo la tierra, sino los enterrados en vida, estos hombres que son como esqueletos de carnes transparentes como las alas de las moscas. ${ }^{22}$

La misma transfiguración del elemento mitológico se hace patente cuando Tabío San discute la leyenda del viento fuerte:

Esperar, como es de creencia aquí, que otro Hermenegildo Puac dé su cabeza al brujo, y que se desencadene un nuevo "viento fuerte", es dejar en manos sobrenaturales problemas que tenemos que resolver nosotros... ${ }^{23}$

Lo que determina en adelante el destino de los mitos originados durante el transcurso de la trilogia bananera es la categoría de su mensaje, su significación social. Las ideas e imágenes concretas que encubren esta significación sucumben a la nueva realidad. Por eso mito y magia, en sus aspectos netamente cognoscitivos, es decir, no adecuados a la realidad, pierden su función en la vida de los protagonistas y ocupan cada vez más una posición periférica en la novela.

Así resulta que Juambo el Sambito no interpreta la leyenda de los ojos de los enterrados según su verdadera significación, sino al pie de la letra. La relaciona con asuntos personales y quiere reparar una injusticia que cree haber cometido contra su padre, trabajando como jalador de frutas. Después de algún tiempo desentierra el cadáver de su padre para ver si tiene los ojos cerrados, ${ }^{24}$ mientras que al mismo tiempo los otros trabajadores preparan la huelga. El mito, privado de su significado social, se convierte en una superstición inútil y sin trascendencia.

22 Ibid, p. 394.

23 Ibid., pp. 474-75.

24 Ibid., pp. 380,382 ff. y otras. 
La transfiguración de los mitos es el problema más importante para la consideración de la relación entre mito y realidad en Los ojos de los enterrados. El mito se justifica en esta novela según el grado en que puede ser factor tradicional y orientador - portador de la esperanzaen la gesta libertadora del pueblo:

Sin embargo, eso es sólo la mitad del problema. En el fondo, casi todas las novelas de Miguel Angel Asturias son creaciones de mitos. Eso ocurre también en Los ojos de los enterrados; y ha sido confirmado por el autor en cuanto, según él explicó la refundición de esta obra, quería al final dar expresión a una esperanza. De ese modo creó un nuevo mito libertador.

Vale la pena investigar los procedimientos usados por Miguel Angel Asturias. La victoria de la revolución guatemalteca sobre la dictadura en 1944 ocurrió del modo siguiente: Después de la caída de varios dictadores centroamericanos, una serie de acciones de protesta tuvieron lugar también en Guatemala, principalmente en la capital, y efectuaron la caída de Ubico. La manifestación más importante tuvo lugar cuando en junio de 1944 los estudiantes dieron al presidente el ultimatum de 24 horas para reabrir la Universidad y garantizar la libertad de la palabra. ${ }^{25}$ El 22 de junio empieza la huelga. Más tarde maestros, médicos y miembros de otras profesiones se unieron a ellos. Después de una manifestación iniciada por los estudiantes el 26 de junio, Ubico trató de sofocar el movimiento, pero sin éxito. Este se ensanchó, y el 29 de junio Ubico tuvo que tetirarse.

Asturias sigue los acontecimientos hasta este punto, y de aquí cn adelante, ellos influyen en los trabajadores de Tiquisate. Pero hay que notar que el 29 de junio de 1944 una junta de generales bajo Federico Ponce se apoderó del gobierno y trató de continuar el régimen de Ubico con nuevo equipo. Sólo el 19 de octubre una insurrección de jóvenes oficiales e intelectuales logró el triunfo de la democracia, y este acontecimiento fue casi en nada precedido de manifestaciones populares. ${ }^{26}$

Hay dos momentos en que Miguel Angel Asturias interpreta libremente los acontecimientos históricos: primero, cuando la dictadura cae, el 29 de junio, como resultado de manifestaciones populares iniciadas por los estudiantes, y segundo, cuando el autor relaciona este suceso di. rectamente con la lucha de los trabajadores bananeros contra el "trust". Eso también es una corrección literaria de lo que ocurrió en 1944, con

25 Véase W. Krehm, Democracia y tiranias en el Caribe (Buenos Aires, 1959), p. 97.

26 Véase ibid., pp. 102-106. 
el propósito de dar expresión a una esperanza, es decir, proyectada hacia el porvenir.

Este manejo libre del material real y concreto es característico del modo de presentación de Asturias. Seymour Menton comenta:

...todos sus libros se basan fuertemente en los acontecimientos y personajes históricos de .Guatemala, sólo que Asturias lo convierte todo en fantasía por medio de su estilo vanguardista. ${ }^{27}$

También en este respecto se puede observar algo esencialmente nuevo en Los ojos de los enterrados. Los mitos hasta entonces creados por el autor eran, en cierto modo, entresacados del material histórico, y sin duda han desempeñado un papel en la toma de conciencia del autor y sus lectores, pero sólo en el sentido de una esperanza incierta. En Los ojos de los enterrados, al contrario, se crea, de acuerdo con la concepción de la novela, el nuevo mito o, como dice Manuel Tuñón de Lara, la prefiguración del día de la tealización ${ }^{28}$ a través de una corrección literaria de los acontecimientos de 1944.

Dentro de la novela latinoamericana actual, Los ojos de los enterrados ocupa un lugar destacado $\mathrm{y}$, en cierto sentido, único entre las dos tendencias del realismo mágico y la novela de tipo existencialista. Con las dos tiene en común que Asturias trata de captar y presentar a sus personajes desde adentro, desde su conciencia. Se distingue de la novela de tipo existencialista por su imagen del hombre que considera como un ser social y popular que sueña en su plena realización como. tal. Parte del realismo mágico que considera como expresión de un ser no enajenado y reproducción del espíritu nacional vivo sobre todo entre los campesinos indígenas a través de un rico patrimonio mitológico y legendario.

La temática de la trilogía bananera planteó el problema de la confrontación del pensamiento mágico con la situación actual del pais. Ante este problema Asturias desarrolló considerablemente sus ideas acerca del mito como fuerza espiritual orientadora de las acciones de los hombres. Descubrió la diferencia entre magia y mito, es decir, entre forma y contenido de la espiritualidad de sus personajes.

La magia como forma que reviste el mito, resulta históricamente relativa. Es un elemento cognoscitivo condicionado por circunstancias históricamente lejanas, superado por la realidad moderna y los instrumentos

\footnotetext{
28 Véase M. Tunón de Lara, "Un romancier social des trópiques: Miguel Angel
} p. 234.

27 S. Menton, Historia crítica de la novela gatatemalteca (Guatemala, 1960), Asturias", Les Temps Modernes, 107 (París, noviembre 1954), p. 657. 
cognoscitivos que ésta brinda a los hombres. Ante el saber humano (y humanístico) moderno, el saber mágico tradicional resulta supersticioso si se considera como método de conocimientos.

Algo distinto sucede con el mito que Asturias tiende a identificar con la esperanza que, a su vez, considera como un anhelo innato del hombre. Es obvio que, directa o indirectamente, esta idea es una prolongación del pensamiento espiritualista bergsoniano. Desde muy temprano Asturias asocia esta metafísica humanista a la idea del "jornal ganado", como escribe en una de sus primeras poesías, ${ }^{29}$ es decir, a la ética del trabajo y el deber. Esto le permite ver, en Los ojos de los enterrados, la realización creadora y libre de los hombres, precisamente en la vida activa de los deberes diarios del hombre de extracción popular, que describe como el forjador de su destino.

Asi, pues, el mito resulta un contenido que, según las circunstancias históricas, reviste formas distintas: desde la mágica hasta la científica. $\mathrm{Si}$ estas formas se revelan como relativas, el mito, como lo concibe Asturias, es un elemento constitutivo del ser humano $y$, por ende, duradero.

$A$ base de esa distinción dialéctica entre mito y magia como contenido y forma, Miguel Angel Asturias logró descubrir una nueva dimensión para el llamado realismo mágico y abrir a la novela latinoamericana una interesante perspectiva de desarrollo.

Adalbert Dessau

Universidad de Rastock, Repriblica Democrática Alemana

29 Véase M. A. Asturias, Obras escogidas (Madrid, 1955), I, pp. 933-934. 